\title{
BENIGN LYMPHOCYTIC INFILTRATION OF SKIN: A CASE REPORT
}

\author{
P. Guru Prasad ${ }^{1}$, R. Rama², S. Jhansi Laxmi³ ${ }^{3}$ Brahma ${ }^{4}$, Padmasri ${ }^{5}$
}

\section{HOW TO CITE THIS ARTICLE:}

P. Guru Prasad, R. Rama, S. Jhansi Laxmi, Brahma, Padmasri. "Benign Lymphocytic Infiltration of Skin: A Case Report". Journal of Evolution of Medical and Dental Sciences 2015; Vol. 4, Issue 28, April 06; Page: 4904-4908, DOI: $10.14260 /$ jemds/2015/713

ABSTRACT: Benign (Jessners) lymphocytic infiltration of the skin is a chronic, benign T-cell infiltrative disorder, usually manifesting as erythematous papules or plaques on the face, neck and back. We report the case of a 30-year - old female, who presented with erythematous papules and plaques on face, upper back, front of chest, of 4 months duration and erythematous plaque on both dorsa of hand and Fore arms of 1 month duration. Skin biopsy confirmed the diagnosis of jessner's lymphocytic infiltration of the skin. The evolution was favorable with hydroxy chloroquine.

KEYWORDS: Benign (Jessners) lymphocytic infiltration of skin, hydroxy chloroquine.

INTRODUCTION: Jessner's (benign) lymphocytic infiltration of the skin (JLIS) is a skin condition of unknown aetiology characterized by erythematous papules and plaques located on the head, neck and upper back. The eruption resolves spontaneously after months or a few years but can recur for several years. A variety of empirical treatments has been tried with limited success. Here we report a case of jessners lymphocytic infiltration of skin successfully treated with hydroxyl chloroquine.

CASE REPORT: A 30 Year old female presented with history of erythematous papules and plaques on the on face, upper back, front of chest, of 4 months duration and erythematous plaque on both dorsa of hand and forearm of 4 month duration. The present complaint started as small erythematous lesion $0.5 \mathrm{~cm}$ size on the fore head, nose, upper back followed by involvement of dorsa fore arms and hands. There is history of increased erythema and burning sensation on exposure to sunlight. There is no history of oral ulcers, arthralgia. No history of aggravation with intake of spicy foods \& alcohol. No history of loss of weight \& loss of appetite. No history of similar complaints in the past. No history of diabetes mellitus, hypertension, jaundice \& psoriasis.

She is moderately built \& moderately nourished, no cyanosis, no clubbing, no jaundice, no generalized lymphadenopathy.

Cutaneous examination (Fig. 1-a, b, c) showed well defined erythematous infiltrated plaque, few erythematous papules and plaques over the fore head, nose upper back, dorsa of forearm and hands. Oral cavity, nails, palms \& soles were normal. 


\section{CASE REPORT}
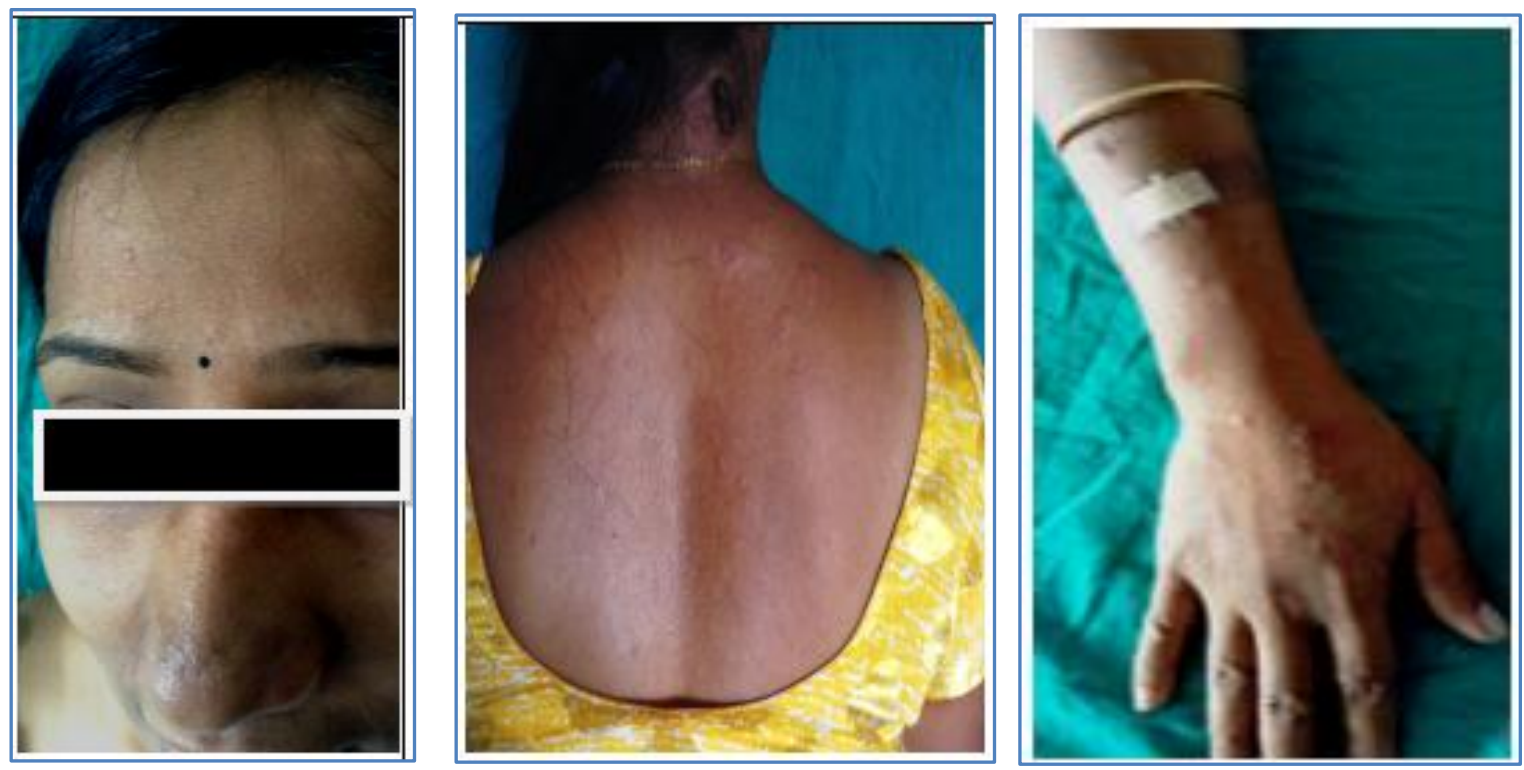

Fig. 1-a, b, c- erythematous papules plaques over face, upper back and dorsum of hands

Differential diagnosis of tumid DLE, Jessners lymphocytic infiltration of the skin, polymorphic light eruption, sarcoidosis and rosacea were considered.

Haematological investigations, renal, liver \& thyroid function tests, borrelia serology, screening for ANA was done. All are with in normal limits. Skin biopsy was taken.

Histopathological findings (Fig. 2 10x\&40x), Epidermis shows focal thinning. Basal layer intact. There is oedema in papillary and upper dermis and congested vessels. There are foci of peirvascular dense lymphoid aggregates and occasional plasma cells. Vascular channels appear to be proliferated with prominent endothelial cells. Collagen in the upper and mid dermis appear swollen and edematous.

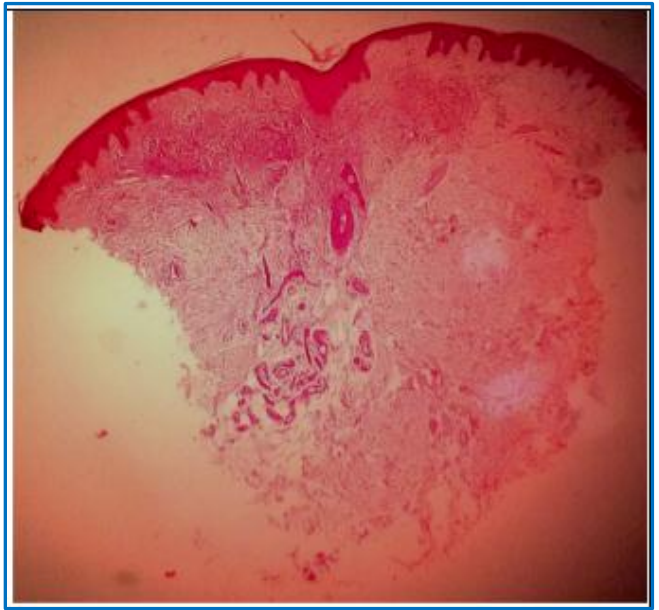

Fig. 2: 10x-congestion and odema of blood vessels in dermis, swollen collagen fibers

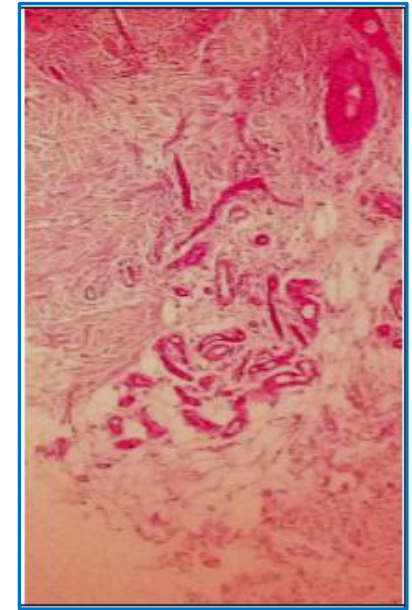

Fig. 2: 40x - perivascular lymphocytic collection, focal proliferation of blood vessels 
Direct immunoflurosence negative.

Mantoux - 7 mm induration.

Chest $\mathrm{x}$ ray was normal.

Basing on history, clinical features and histopathological findings diagnosis of jessners (benign) lymphocytic infiltration of the skin was made.

After confirming the diagnosis, we put the patient on Tab. Hydroxy chloroquine $200 \mathrm{mg}$ BID tapered over a period of 6 weeks along with topical sunscreen.

Skin lesions subsided after 6 weeks treatment (Fig. 3). Treatment was stopped and the patient was followed up for 1 year. There was no recurrence of the lesions till now.

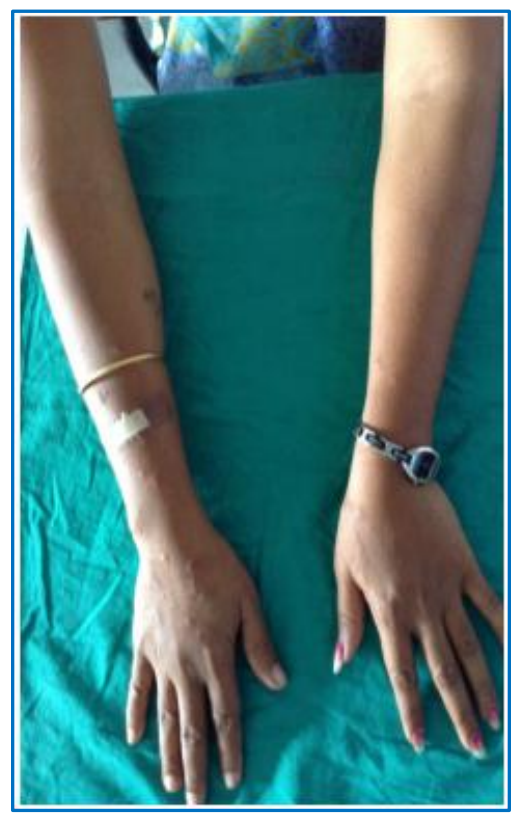

Fig. 3: Before Treatment

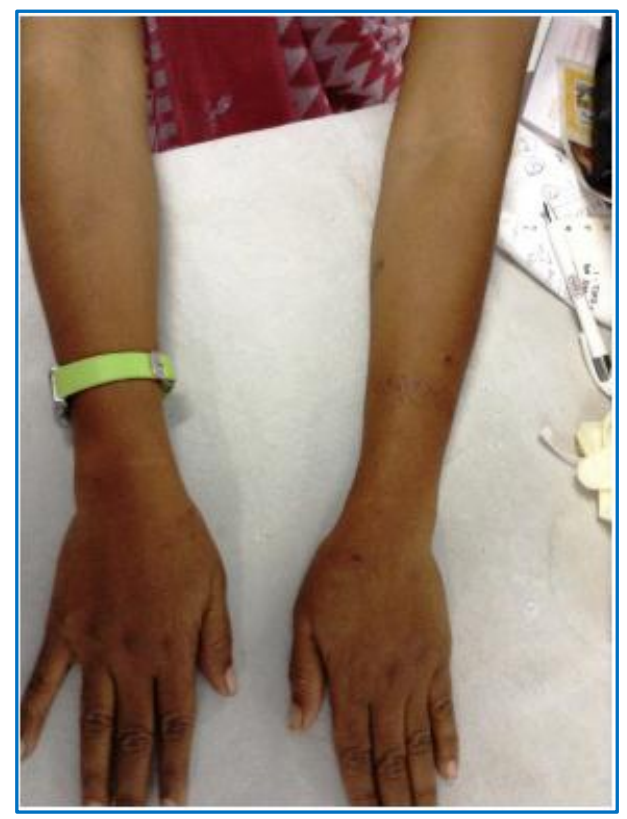

Fig. 3: After Treatment

DISCUSSION: JLIS, described by Jessner \& Kanof in 1953,(1) is known as a benign chronic T-cell infiltrative disorder with lesions persisting for several months or years. Spontaneous remission may be seen, but JLIS has a tendency to relapse.

The incidence of JLIS is unknown, but it is considered uncommon. It mostly affects middleaged adults, with equal incidence in men and women, and very rarely occurs in children.(2,3) Familial occurrence has been described in the literature. $(4,5)$ In our case patient is an middle aged female presenting for the first time.

JLIS is characterized by single or multiple erythematous papules or plaques and, less commonly, nodules, typically localized on the face, neck, chest, arms and upper back.(3) Our case also presented with similar features.

Sometimes an arciform configuration with central clearing is seen. Usually the lesions are asymptomatic, but they can be itching or burning. The relationship to sun exposure is variable and there is no regional variation in incidence.(3) In our case history of aggravation on exposure to sunlight is present. 
Whether JLIS is a separate entity, or belongs to the disease spectrum of cutaneous lupus erythematosus or polymorphous light eruption is still a matter of debate, since clinical and histopathological features may overlap in particular with lupus erythematosus tumidus. Recent comprehensive studies conclude that these two conditions share more similarities than differences. ${ }^{2,6)}$ A few cases related to Borrelia burgdorferi infection or drugs have been reported.(7,8) Also, a few cases have been ascribed to contact allergy. ${ }^{(9)}$

Histopathologically JLIS is characterized by a superficial and deep, primarily perivascular, sleeve-like lymphocytic dermal infiltrate with a predominance of small mature polyclonal lymphocytes and without epidermal involvement.(2,10) Deposits of mucin in the reticular dermis have been described.(6) However, other authors have been unable to demonstrate mucin in JLIS.(2,11) in our case histopathology is in corelation with previous studies.

A variety of treatments has been tried, with variable, and often limited, success, including topical, intra-lesional or systemic corticosteroids, antimalarials, thalidomide, tetracyclines, cryotherapy and photo-protection. A few cases of successful treatment with dapsone, auranofin, and chemotherapy have been reported.(12-14)

In our case there was good response to hydroxy chloroquine $200 \mathrm{mg}$ bid, this is in concurance with previous studies.(15),(16) Treatment with anti- malarials is usually effective in case with photosensitivity (Adamski et al. 2002).(17) In our case the evolution case is favourable with antimalarials

Patient is under remission after 6 weeks. 1 year follow up was done, there were no recurrences. Prognosis is good, because lymphocytic infiltration of skin resolves spontaneously.

\section{REFERENCES:}

1. Jessner M, Kanof B. Lymphocytic infiltration of the skin. Arch Dermatol 1953; 68: 447-449.

2. Lipsker D, Mitschler A, Grosshans E, Cribier B. Could Jessner's lymphocytic infiltrate of the skin be a dermal variant of lupus erythematosus? An analysis of 210 cases. Dermatology 2006; 213: 15-22.

3. Toonstra J, Wildschut A, Boer J, Smeenk G, Willemze R, van der Putte SC, et al. Jessner's lymphocytic infiltration of the skin. A clinical study of 100 patients. Arch Dermatol 1989; 125: 1525-1530.

4. Dippel E, Poenitz N, Klemke CD, Orfanos CE, Goerdt S. Familial lymphocytic infiltration of the skin: histochemical and molecular analysis in three brothers. Dermatology 2002; 204: 12-16.

5. Ashworth J, Morley WN. Jessner and Kanof's lymphocytic infiltration of the skin: a familial variant. Dermatologica 1988; 177: 120-122.

6. Rémy-Leroux V, Léonard F, Lambert D, Wechsler J, Cribier B, Thomas P, et al. Comparison of histopathologic-clinical characteristics of Jessner's lymphocytic infiltration of the skin and lupus erythematosus tumidus: multicenter study of 46 cases. J Am Acad Dermatol 2008; 58: 217-223.

7. Abele DC, Anders KH, Chandler FW. Benign lymphocytic infiltration (Jessner-Kanof): another manifestation of borreliosis? J Am Acad Dermatol 1989; 21: 795-797.

8. Schepis C, Lentini M, Siragusa M, Batolo D. ACE-inhibitor-induced drug eruption resembling lymphocytic infiltration (of Jessner-Kanof) and lupus erythematosus tumidus. Dermatology 2004; 208: 354-355. 


\section{CASE REPORT}

9. Caroli UM, Berner D, Schlegel C, Metzler G, Röcken M, Biedermann T. Lymphocytic infiltration of the skin Jessner-Kanof after treatment with a hydroquinone-containing bleaching cream. Arch Dermatol 2006; 142: 1655-1656.

10. Poenitz N, Dippel E, Klemke CD, Qadoumi M, Goerdt S. Jessner's lymphocytic infiltration of the skin: a CD8+ polyclonal reactive skin condition. Dermatology 2003; 207: 276-284.

11. Teixeira M, Ferreira M, Alves R, Selores M. Lupus erythematosus tumidus: an underestimated entity. Lupus 2006; 15: 296-300.

12. Ardavanis A, Orphanos G, Skafida S, Basioukas S, Rigatos G. Coincidential successful treatment of Jessner-Kanof disease with chemotherapy. Ann Oncol 2008; 19: 1360-1361.

13. Rai VM, Balachandran C. Multiple infiltrated nodules and plaques. Lymphocytic infiltrate of Jessner. Dermatol Online J 2006; 12: 26.

14. Hafejee A, Winhoven S, Coulson IH. Jessner's lymphocytic infiltrate responding to oral auranofin. J Dermatolog Treat 2004; 15: 331-332.

15. Hügel R, Schwarz T, Gläser R. Resistance to hydroxychloroquine due to smoking in a patient with lupus erythematosus tumidus. Br J Dermatol 2007; 157: 1081-1083.

16. Rasa Laurinaviciene1, Ole Clemmensen 2 and Anette Bygum $1 *$ Departments of 1Dermatology and 2Pathology, Odense University Hospital, DK-5000 Odense, Denmark. Successful Treatment of Jessner's Lymphocytic Infiltration of the Skin with Methotrexate *E-mail: anette. bygum@ouh. regionsyddanmark. dk Accepted May 25, 2009.

17. Journal of Saudi Society Of dermatology \& dermatologic surgery (2012) 16, 77-79.
AUTHORS:
1. P. Guru Prasad
2. R. Rama
3. S. Jhansi Laxmi
4. Brahma
5. Padmasri

\section{PARTICULARS OF CONTRIBUTORS:}

1. Associate Professor, Department of DVL, Andhra Medical College, Visakhapatnam.

2. Assistant Professor, Department of DVL, Andhra Medical College, Visakhapatnam.

3. Assistant Professor, Department of DVL, Andhra Medical College, Visakhapatnam.

4. Junior Resident, Department of DVL, Andhra Medical College, Visakhapatnam.

FINANCIAL OR OTHER COMPETING INTERESTS: None
5. Junior Resident, Department of DVL, Andhra Medical College, Visakhapatnam.

\section{NAME ADDRESS EMAIL ID OF THE CORRESPONDING AUTHOR:}

Dr. P. Guru Prasad, Associate Professor, Department of Dermatology, King George Hospital, Andhra Medical College, Maharanipeta, Visakhapatnam-530002, Andhra Pradesh, India.

E-mail: gppatnala@yahoo.co.in

Date of Submission: 06/02/2015. Date of Peer Review: 07/02/2015. Date of Acceptance: 23/03/2015. Date of Publishing: 06/04/2015. 